\title{
The Role of Emotional Intelligence on Health Care Professionals Occupational Stress and Burnout
}

\section{Swarnima Tiwari ${ }^{1}$, Deepak Bhagat ${ }^{2}$}

Section: Healthcare

Sci. Journal Impact

Factor: 6.1 (2018)

ICV: 90.90 (2018)

(c) (7) (3)

Copyright@IJCRR
'Research Scholar, Department of Management, North-East Hill University, Tura, Meghalaya 794001, India; ${ }^{2}$ Assistant Professor, Department of Management, North-East Hill University, Tura, Meghalaya 794001, lndia.

\section{ABSTRACT}

Introduction: Though relevance and importance of emotional intelligence have been documented in various fields, yet, the emotional intelligence dimension of health care professionals has not been given adequate attention and very little empirical research has examined the role of El on occupational stress.

Objective: To systematically explore and describe the relationship between El and the dimensions of occupational stress.

Methods: To this aim, a sample of 257 nurses and 131 doctors working in hospitals, PHC's, CHC's, \& sub-centres were selected from all the hospitals, CHC's, and PHC's. The study included 4 questionnaires: Emotional Quotient Test, Occupational Stress Index (OSI), Oldenburg Burnout Inventory (OLBI), and Perceived stress scale (PSS). Data obtained were analyzed using ANOVA, Pearson correlation, and multiple regression.

Results: The results highlighted an inverse significant relationship between the dimensions of occupational stress and emotional intelligence. Additionally, a positive relationship was also found between age, working experience, and stress, with younger healthcare professionals and those with a shorter length of service experiencing more stress. However, El and health are not related to age or length of service.

Conclusion: The study concluded that emotional intelligence can help in reducing occupational stress among health care not only by decreasing or controlling the stressors present in the workplace but also by increasing the potential of employees to effectively deal with those stressors.

Key Words: Emotional Intelligence, Occupational Stress, Burnout, Perceived Stress, Healthcare, Doctors, Nurses

\section{INTRODUCTION}

For long the emotional component of human service, though crucial, but has been ignored. Within the many contexts in the present complex healthcare system, numerous experiences and expressions of emotions occur, ranging from providers disclosing bad news to patients to offering emotional support to hospitalized or institutionalized patients. Emotions are fundamental to health care and crucial to providing empathetic and patient-focused care. ${ }^{1}$ The present healthcare system is experiencing a change with pressures to make the health care system more efficient, the attendant being more focused towards rationalization, managed care, and curtailment of care and services ${ }^{1}$ apart from these work overload, time tables, interpersonal conflicts, shift work, dealing with deaths and seriously ill patients and lack of mental support.
Stress occurs in response to a lack of ability to cope up with the stressor present in the work- setting ${ }^{2}$ resulting in making mistakes with negative outcomes such as depression, ${ }^{3}$ decreased professional satisfaction, ${ }^{4}$ disrupted personal relationships, ${ }^{5}$ psychological distress ${ }^{6}$, and even suicide. ${ }^{7,8}$

One of the ways to deal with occupational stress is through the management of emotions, which is now being considered by intellectuals more than ever. Studies in psychology have also highlighted that success at work-life does not depend on IQ and it determines only $20 \%$ of a person's success, but rather it depends on a person's emotional intelligence which determines $80 \%$ of success. ${ }^{9}$ Emotional intelligence assumes that emotions are the essence of life and different persons differ in their ability in perceiving understanding, and managing emotions in themselves and others; which in turn af-

\section{Corresponding Author:}

Swarnima Tiwari, Research Scholar, Department of Management, North-East Hill University, Tura, Meghalaya 794001, India. Email: swartiwari@gmail.com

ISSN: 2231-2196 (Print)

Received: 30.07 .2020
ISSN: 0975-5241 (Online)

Revised: 03.10 .2020
Accepted: 21.10 .2020
Published: 14.12 .2020 
fect their adaptableness to different environmental contexts, including the workplace..$^{10}$ In the Western countries, there is a greater awareness and sensitivity to the problems that are faced by healthcare professionals and several studies have focused on the importance of emotional intelligence training in the health care profession as a means for preventing stress and burnout, and for improving communication skills and performance. ${ }^{11-14}$

The healthcare system in Meghalaya is strangled due to the serious shortage of specialized medical and para-medical staff, infrastructure facilities, drugs, etc. Apart from these the hilly topography and poor road infrastructure are making the health sector scenario even worst making their life stressful. Under the circumstances, health care professionals need to learn how to cope and control strong emotions so that they can provide better services. However, researchers dealing with health care sectors have ignored the occupational stress and emotional intelligence dimension of health care professionals. ${ }^{12}$ The present study intends to fill this gap by exploring the emotional intelligence dimension of health care professionals in dealing with stressful situations. The present study proposes to measure the extent of occupational stress and level of emotional intelligence of health care professionals and study the relationship between emotional intelligence and occupational stress of health care professionals.

\section{MATERIALS AND METHODS}

\section{(a) Instruments and Measures}

The present research uses a conceptual model to study the relationship between emotional intelligence and occupational stress and burnout. This model was made by the represented test of the Emotional Quotient Test, Occupational Stress Index, Oldenburg Burnout Inventory (OLBI), and Perceived Stress Scale (PSS) (Figure 1). In this study, emotional intelligence is considered as an independent variable, and variables occupational stress and burnout are considered as the dependant variable.

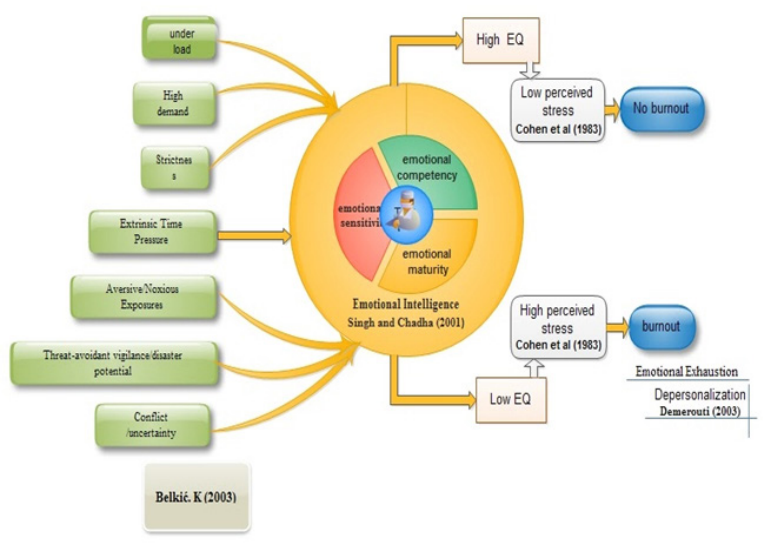

Figure 1: Research Framework of the Study.

\section{Sample and Data Colelction}

To examine the relationships between Emotional intelligence, occupational stress, and burnout, 131 doctors and 257 nurses working in all the hospitals as well as PHC's, CHC's, and sub-centres were selected. All the four tests were administered on two groups of healthcare professionals, that is, Doctors and Nursing Staff in selected hospitals/CHC/PHC/ UHC. Throughout the testing, the doctors and nurses were informed that their responses are anonymous and confidential, and the collected data will not be used for any professionals or healthcare evaluation. The tests were administered in the following sequence to all the respondents: Emotional Intelligence ${ }^{15}$, Occupational Stress Index ${ }^{16}$, Perceived Stress Scale $^{17}$, and Oldenburg Burnout Inventory. ${ }^{18}$

\section{Statistical Analyses}

The obtained data were subjected to several statistical analyses pertinent to the research objectives of the study. To test the significance of mean difference across different professional groups and gender, ANOVA was applied. The correlations among variables were obtained by applying Pearson's Product Moment method. Regressions of Burnout on Occupational Stress and Emotional Intelligence were computed by employing standard multiple regression analyses.

\section{RESULTS AND DISCUSSION}

\section{Occupational Stress \& Emotional Intelligence of Health Care Professionals}

Table 1 describes the mean, S.D, and the relation between occupational stress and emotional intelligence related to demographic variables for the sample under investigation. The results showed a high level of occupational stress among doctors and nurses and doctors and nurses differ significantly on occupational stress and the mean OSI score for nurses was high as compared to doctors. Concerning gender, the results indicated that females experienced more stress as compared to male healthcare professionals with a mean of [76.00 (S.D=9.51)] for males and [79.83 (S.D=8.65)] (p-value 0.002 ) (Table 1). The results also highlighted a difference in mean scores of respondents based on the age group they belong to. It is found that respondent with the younger age group that is 20-30 years experience high stress followed by the age group 30-40 years. It was also found that there exists a difference based on the marital status of the respondents, number of dependents, working experience, and income. However, the living arrangement of the respondents shows a non-significant difference. Results confirmed that socio-demographic variables of healthcare professionals significantly influenced occupational stress. The results are comparable to some earlier studies. ${ }^{19-21}$ 
Table 1: Mean and standard deviation related to the demographic variables

\begin{tabular}{|c|c|c|c|c|c|}
\hline \multirow[t]{2}{*}{ Variable } & & \multicolumn{2}{|c|}{ Occupational Stress } & \multicolumn{2}{|c|}{ Emotional Intelligence } \\
\hline & & Mean \pm SD & $\mathbf{P}$ & Mean \pm SD & $\mathbf{P}$ \\
\hline \multirow[t]{2}{*}{ Occupational groups } & Doctor & $76.49 \pm 9.78$ & 0.000 & $325.88 \pm 45.80$ & \multirow{2}{*}{.000} \\
\hline & Nurse & $80.47 \pm 8.16$ & & $307.93 \pm 45.80$ & \\
\hline \multirow[t]{2}{*}{ Gender } & Male & $76.00 \pm 9.51$ & 0.002 & $328.80 \pm 43.63$ & \multirow{2}{*}{.000} \\
\hline & Female & $79.83 \pm 8.65$ & & $310.66 \pm 40.25$ & \\
\hline \multirow[t]{4}{*}{ Age } & 20 to 30 & $82.30 \pm 8.25$ & 0.000 & $301.60 \pm 34.17$ & \multirow{4}{*}{0.000} \\
\hline & 30 to 40 & $79.24 \pm 7.97$ & & $310.80 \pm 41.00$ & \\
\hline & 40 to 50 & $75.63 \pm 8.25$ & & $325.71 \pm 41.88$ & \\
\hline & 50 to 60 & $71.93 \pm 10.41$ & & $342.21 \pm 47.07$ & \\
\hline \multirow[t]{4}{*}{ Marital Status } & Married & $78.58 \pm 9.04$ & 0.005 & $316.51 \pm 42.09$ & \multirow{4}{*}{0.003} \\
\hline & Single & $80.82 \pm 7.95$ & & $305.99 \pm 36.00$ & \\
\hline & Widow & $80.55 \pm 13.79$ & & $307.00 \pm 62.41$ & \\
\hline & Separated & $69.29 \pm 10.80$ & & $363.33 \pm 54.65$ & \\
\hline \multirow[t]{4}{*}{ Living Arrangement } & Living with family & $78.30 \pm 8.96$ & 0.012 & $317.67 \pm 41.55$ & \multirow{4}{*}{0.017} \\
\hline & Living with one or more & $81.02 \pm 7.54$ & & $304.38 \pm 34.09$ & \\
\hline & Living with a partner only & $84.31 \pm 8.90$ & & $292.35 \pm 39.65$ & \\
\hline & Living alone & $79.21 \pm 9.70$ & & $314.80 \pm 46.72$ & \\
\hline \multirow[t]{3}{*}{ Number of dependent } & o to 2 & $79.62 \pm 8.73$ & 0.008 & $312.08 \pm 40.31$ & \multirow{3}{*}{0.009} \\
\hline & 3 to 5 & $77.19 \pm 8.93$ & & $322.11 \pm 41.78$ & \\
\hline & 6 to 8 & $86.63 \pm 12.62$ & & $275.83 \pm 62.24$ & \\
\hline \multirow[t]{6}{*}{ Working Experience } & o to 5 yrs & $82.30 \pm 8.50$ & 0.000 & $300.40 \pm 38.50$ & \multirow{6}{*}{0.000} \\
\hline & 5 to $10 \mathrm{yrs}$ & $78.76 \pm 8.47$ & & $314.52 \pm 40.04$ & \\
\hline & 10 to $15 \mathrm{yrs}$ & $76.64 \pm 7.38$ & & $325.46 \pm 32.96$ & \\
\hline & 15 to $20 \mathrm{yrs}$ & $72.21 \pm 10.79$ & & $346.55 \pm 50.76$ & \\
\hline & 20 to $25 \mathrm{yrs}$ & $75.50 \pm 9.43$ & & $332.50 \pm 55.10$ & \\
\hline & above 25 & $82.13 \pm 2.17$ & & $298.75 \pm 13.15$ & \\
\hline \multirow[t]{4}{*}{ Income } & o to 2 lakh & $82.47 \pm 7.37$ & 0.000 & $299.09 \pm 32.37$ & \multirow{4}{*}{0.000} \\
\hline & 2 to 4 lakh & $80.44 \pm 7.90$ & & $307 \cdot 76 \pm 36.10$ & \\
\hline & 4 to 6 lakh & $76.28 \pm 9.62$ & & $327.52 \pm 45.66$ & \\
\hline & 6 to 8 lakh & $76.02 \pm 10.21$ & & $326.36 \pm 49.15$ & \\
\hline
\end{tabular}

Results based on (ANOVA and t-test)

As indicated in table 1 emotional intelligence vary according to the age of the respondents $(\mathrm{p}<.001)$ and the age group of 50-60 years has scored highest (342.2) on emotional intelligence. This implies that age has a significant role to play in the healthcare professional's emotional intelligence. This indicates the development of EQ with age. The variation in scores, i.e., the standard deviation is also found to be higher in the older group. This shows that the older age group among health care professionals is higher on EQ than the younger age group. In other words, it appears that EQ is dependent on age. Similar results have been found in another study $^{22,23}$ where it was found that EQ is dependent on age. When EQ was compared based on the marital status of the healthcare professionals it was found that emotional intelli- gence varies according to the marital status of the healthcare professionals and healthcare professionals who are either not married or single have the lowest EQ. In the case of living arrangement, it was found that there is no significant difference between the mean value of $\mathrm{EI}$ ( $\mathrm{p}$-value $=0.17$ ). For the number of dependent significant difference was found in the emotional intelligence score of the healthcare professionals $(p$-value $=.009)$ with healthcare professionals with more dependent scoring lowest in EQ. In tune with working experience, a significant difference was found between the healthcare professionals $(\mathrm{p}<.001)$, and healthcare professionals with working experience of 15-20 years have reported the highest EQ. With regards to income, a significant difference was found in the emotional intelligence score of the health- 
care professionals $(\mathrm{p}<.001)$ with health care professionals in the income group of 4-6 lakh and 6-8 lakh have reported scoring highest on EQ (Table 1).

\section{Perceived Stress and Burnout of Health Care Professionals}

Inspection of Table 2 indicates that significant differences have been observed among the two groups in the means scores of perceived stress, burnout, and its two dimensions of emotional exhaustion and depersonalization. The mean perceived stress score for doctors (13.95) and nurses (15.60) indicates a significant difference $(\mathrm{p}<.001)$. Results also indicate that there exist a significant difference in the mean score of Emotional Exhaustion [doctors (18.31), nurses (20.21) $(\mathrm{p}<.001)$ ] and depersonalization [doctors $(17.11)$, nurses $(18.52)(\mathrm{p}<.001)]$ (Table 2) dimensions of burnout. This depicts that doctors and nurses differ in these two dimensions of burnout. For perceived stress, burnout, and its two dimensions, the mean score of nurses is higher than doctors. This shows that perceived stress and burnout is experienced more by nurses than doctors.

Table 2: Mean Perceived Stress and Burnout

\begin{tabular}{llrc} 
Variables & Category & Mean \pm SD & p \\
Perceived Stress & Doctor & $13.95 \pm 4.53$ & 0.001 \\
& Nurse & $15.60 \pm 3.76$ & \\
Burnout & Doctor & $35.37 \pm 8.45$ & 0.001 \\
& Nurse & $38.73 \pm 7.02$ & \\
Emotional Exhaus- & Doctor & $18.31 \pm 4.38$ & 0.001 \\
tion & Nurse & $20.21 \pm 3.74$ & \\
Depersonalization & Doctor & $17.11 \pm 4.30$ & 0.001 \\
& Nurse & $18.52 \pm 3.48$ & \\
\hline
\end{tabular}

Correlation between Emotional Intelligence, Occupational Stress, Perceived Stress and Burnout of Health Care Professionals

To investigate the relationship between different variables Pearson's correlations were computed for the two occupational groups of healthcare professionals- Doctors and nurses (Table 3). The inter-correlations among the dimensions of emotional intelligence, occupational stress, burnout, and perceived stress are presented under separate headings. To have a convenient comparison, all three groups were taken at the same time.

Results of the correlation analysis for doctors and nurses reveal that emotional intelligence and its three dimensions emotional sensitivity, emotional maturity, and emotional competency had a significant negative correlation with the dimensions of occupational stress, perceived stress, and burnout, which indicates that where respondents report a lower level of emotional intelligence it is more likely that they will report higher levels of occupational stress and vice versa. These suggest that an increase in the level of emotional intelligence could have a negative impact on the level of reported stress and burnout.

Further, the result of correlations also indicates a significant positive correlation between the dimensions of occupational stress, perceived stress, and burnout for doctors and nurses. This means that high perceived stress is related to high occupational stress and burnout in healthcare.

Table 3: Correlations between dimensions of Emotional Intelligence, Occupational stress, burnout and perceived stress for doctors and nurses

\begin{tabular}{|c|c|c|c|c|c|c|c|c|c|c|c|}
\hline Var. & & UL & HD & ST & ETP & NE & TA & $\mathrm{CN}$ & EE & DP & PSS \\
\hline \multirow[t]{2}{*}{ ES } & Doc & $-0.282^{* * *}$ & $-0.865^{* *}$ & $-0.793^{* *}$ & $-0.779^{* *}$ & $-0.868^{* *}$ & $-0.726^{* *}$ & $-0.880^{* *}$ & $-0.774^{* *}$ & $-.820^{* * *}$ & $-0.761^{* *}$ \\
\hline & Nurse & $-0.603^{* *}$ & $-0.754^{* *}$ & $-0.780^{* *}$ & $-0.812^{* *}$ & $-0.805^{* *}$ & $-0.723^{* * *}$ & $-.817^{* *}$ & $-0.823^{* * *}$ & $-.773^{* *}$ & $-0.795^{*}$ \\
\hline \multirow[t]{2}{*}{ EM } & Doc & $-0.243^{* *}$ & $-0.873^{* *}$ & $-0.805^{* *}$ & $-0.786^{* *}$ & $-0.870^{* *}$ & $-0.826^{* *}$ & $-0.881^{* *}$ & $-0.819^{* *}$ & $-0.834^{* *}$ & $-0.766^{*}$ \\
\hline & Nurs & $-0.584^{* *}$ & $-0.768^{* *}$ & $-0.803^{* *}$ & $-0.774^{* *}$ & $-0.772^{* * *}$ & $-0.720^{* *}$ & $-0.784^{* *}$ & $-0.764^{* *}$ & $-0.777^{* *}$ & $-0.770^{*}$ \\
\hline \multirow[t]{2}{*}{ EC } & Doc & $-0.281^{* *}$ & $-0.909^{* *}$ & $-0.783^{* *}$ & $-0.856^{* *}$ & $-0.910^{* *}$ & $-0.816^{* *}$ & $-0.924^{* *}$ & $-0.827^{* *}$ & $-0.831^{* *}$ & $-0.770^{*}$ \\
\hline & Nurse & $-0.651^{* *}$ & $-0.831^{* *}$ & $-0.880^{* *}$ & $-.870^{* *}$ & $-0.894^{* *}$ & $-0.794^{* *}$ & $-0.903^{* *}$ & $-0.841^{* *}$ & $-0.893^{* *}$ & $-0.852^{*}$ \\
\hline \multirow[t]{2}{*}{ EI } & Doc & $-0.294^{* *}$ & $-0.971^{* *}$ & $-0.869^{* *}$ & $-.892^{* *}$ & $-0.972^{* *}$ & $-0.874^{* *}$ & $-0.985^{* *}$ & $-0.889^{* *}$ & $-0.910^{* *}$ & $-0.840^{*}$ \\
\hline & Nurse & $-0.706^{* *}$ & $-0.905^{* *}$ & $-0.950^{* *}$ & $-0.942^{* *}$ & $-0.952^{* *}$ & $-0.86 \mathrm{o}^{* *}$ & $-0.964^{* *}$ & $-0.926^{* *}$ & $-0.945^{* *}$ & $-0.927^{* *}$ \\
\hline
\end{tabular}

${ }^{* *}$ Correlation is significant at the o.or level (2-tailed).

ES: Emotional Sensitivity, EM: Emotional Maturity, EC: Emotional Competency, EI: Emotional Intelligence, UL: Under load, HD: High Demand, ST: Strictness, ETP: Extensive Time Pressure, NE: Noxious Exposure, TA: Threat Avoidance, CU: Conflict, OS: Occupational Stress, EE: Emotional Exhaustion, DP: Depersonalization, BU: Burnout, PSS: Perceived Stress 


\section{Relationship between Emotional Intelligence, Occupational Stress, Perceived Stress and Burnout}

To determine which dimensions of emotional intelligence predicts the greatest variance in the dimensions of occupational stress burnout and perceived stress, a series of standard multiple regressions were performed between the dimensions of occupational stress (under load, high demand, strictness, extrinsic time pressure, noxious exposures, threat avoidance, conflict/uncertainty), burnout (emotional exhaustion and depersonalization) and perceived stress respectively as a dependent variable and various dimensions of Emotional Intelligence (Emotional Sensitivity, Emotional Maturity, and Emotional Competency) as independent variables. The results are presented in Tables 4 to 13 .
Table 4 presents the results of the standard regression for the dependent variable under load, as a dimension of occupational stress among doctors and nurses. Results for doctors indicated that none of the predicting variables has been found contributing significantly towards predicting under load. The results from the sample of nurses indicated that the model was significant $(\mathrm{p}<0.001)$ and that it explained $49 \%$ variance in under load. All the three predictor variables entered into the regression model made a unique contribution in explaining the variance in under load and with one unit change in the predictors. Emotional sensitivity, emotional maturity, and emotional competency record a corresponding change of $0.002,0.001,0.001$ respectively (Table 4 ).

Table 4: Relationship of Emotional Intelligence with Under Load

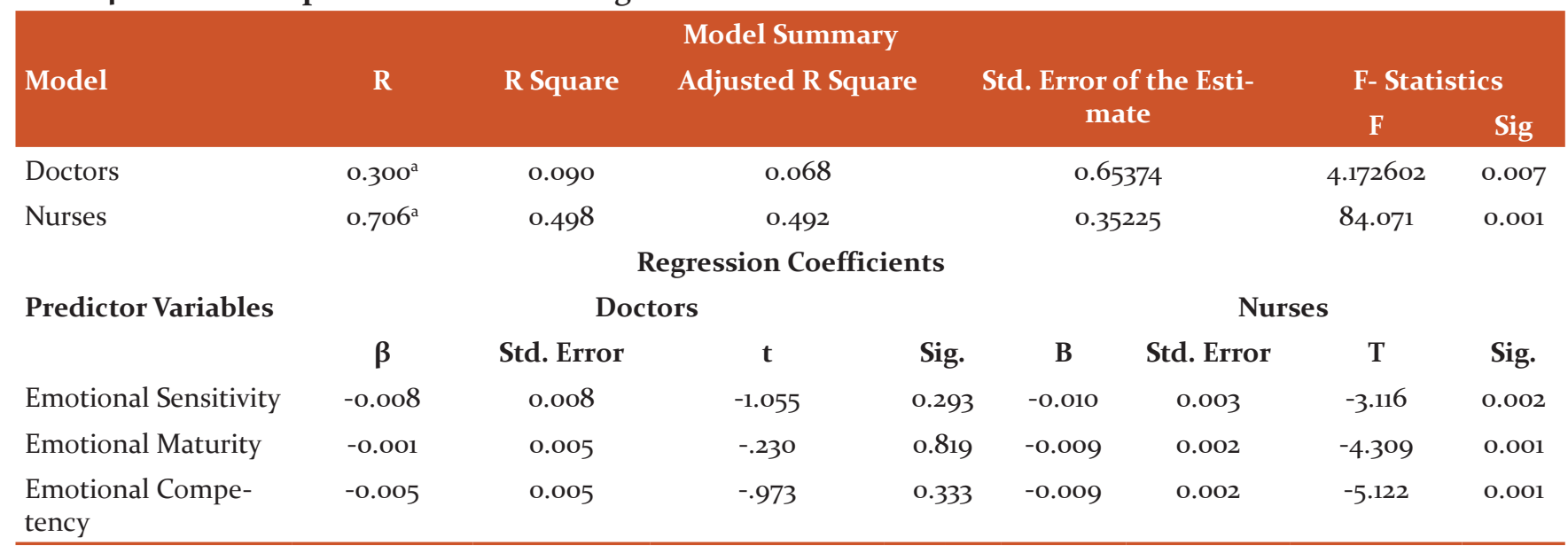

The results presented in Table 5, indicated that the three predictor variables emotional sensitivity, emotional maturity, and emotional competency contributed $94 \%$ (doctors) and
$81 \%$ (nurses) of variance in high demand. The contributions made by all the three dimensions of emotional intelligence on high demand were significant (Table 5).

Table 5: Relationship of Emotional Intelligence with High Demand

\begin{tabular}{|c|c|c|c|c|c|c|c|c|}
\hline \multicolumn{9}{|c|}{ Model Summary } \\
\hline \multirow{2}{*}{ Model } & \multirow[t]{2}{*}{$\mathbf{R}$} & \multirow[t]{2}{*}{ R Square } & \multirow{2}{*}{\multicolumn{2}{|c|}{ Adjusted R Square }} & \multirow{2}{*}{\multicolumn{2}{|c|}{$\begin{array}{l}\text { Std. Error of the Esti- } \\
\text { mate }\end{array}$}} & \multicolumn{2}{|c|}{ F- Statistics } \\
\hline & & & & & & & $\mathbf{F}$ & Sig \\
\hline Doctors & 0.971 & 0.943 & \multicolumn{2}{|c|}{0.942} & \multicolumn{2}{|l|}{0.55197} & 702.823 & 0.001 \\
\hline Nurses & 0.906 & 0.820 & \multicolumn{2}{|c|}{0.818} & 0.79708 & & 385.531 & 0.001 \\
\hline \multicolumn{9}{|c|}{ Regression Coefficients } \\
\hline \multirow[t]{2}{*}{ Predictor Variables } & \multicolumn{4}{|c|}{ Doctors } & \multicolumn{4}{|c|}{ Nurses } \\
\hline & $\beta$ & $\begin{array}{l}\text { Std. } \\
\text { Error }\end{array}$ & t & Sig. & B & Std. Error & $\mathbf{t}$ & Sig. \\
\hline Emotional Sensitivity & -0.049 & 0.007 & -7.543 & 0.001 & -0.041 & 0.007 & -5.485 & 0.001 \\
\hline Emotional Maturity & -0.048 & 0.004 & -10.741 & 0.001 & -0.050 & 0.005 & -10.519 & 0.001 \\
\hline $\begin{array}{l}\text { Emotional Compe- } \\
\text { tency }\end{array}$ & -0.049 & 0.004 & -12.045 & 0.001 & -0.043 & 0.004 & -11.023 & 0.001 \\
\hline
\end{tabular}


The results presented in Table 6, indicated that the three predictor variables emotional sensitivity, emotional maturity, and emotional competency contributed $75 \%$ (doctors) and
$90 \%$ (nurses) of variance in strictness. The contributions made by all the three dimensions of Emotional intelligence on strictness were significant.

Table 6: Relationship of Emotional Intelligence with Strictness

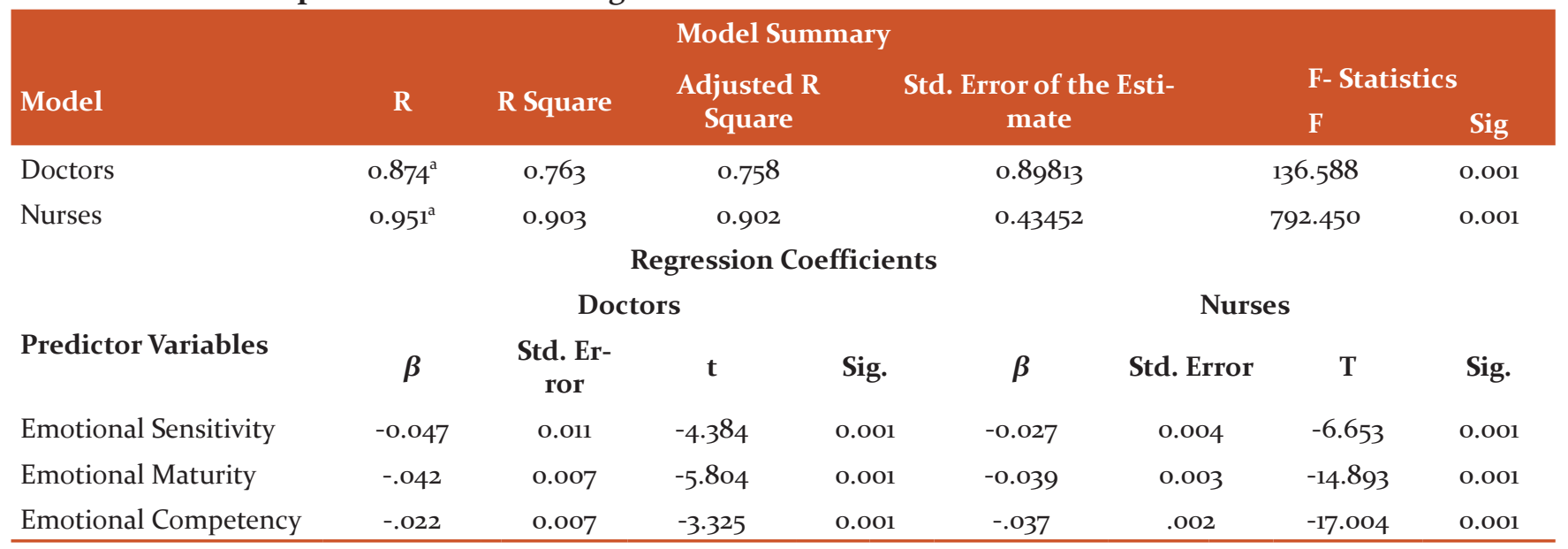

The results presented in Table 7, indicated that the three predictor variables emotional sensitivity, emotional maturity, and emotional competency contributed 79\% (doctors) and $88 \%$ (nurses) of variance in extrinsic time pressure. The contributions made by all the three dimensions of emotional intelligence on extrinsic time pressure were significant.

\section{Table 7: Relationship of Emotional Intelligence with Extrinsic Time Pressure}

\begin{tabular}{|c|c|c|c|c|c|c|c|c|}
\hline \multicolumn{9}{|c|}{ Model Summary } \\
\hline Model & $\mathbf{R}$ & R Square & \multirow{2}{*}{\multicolumn{2}{|c|}{$\begin{array}{l}\text { Adjusted R } \\
\text { Square }\end{array}$}} & Std. Error of & & \multicolumn{2}{|c|}{ F- Statistics } \\
\hline & & & & & Estimate & & $\mathbf{F}$ & Sig \\
\hline Doctors & $0.894^{\mathrm{a}}$ & 0.799 & \multicolumn{2}{|c|}{0.794} & 0.28411 & \multicolumn{2}{|c|}{168.417} & 0.001 \\
\hline Nurses & $0.943^{\mathrm{a}}$ & 0.889 & \multicolumn{2}{|c|}{0.887} & 0.19489 & \multicolumn{2}{|c|}{676.733} & 0.001 \\
\hline \multicolumn{9}{|c|}{ Regression Coefficients } \\
\hline \multirow[t]{2}{*}{ Predictor Variables } & \multicolumn{4}{|c|}{ Doctors } & \multicolumn{4}{|c|}{ Nurses } \\
\hline & $\beta$ & Std. Error & $\mathbf{t}$ & Sig. & $\beta$ & Std. Error & $\mathbf{t}$ & Sig. \\
\hline Emotional Sensitivity & -0.009 & 0.003 & -2.780 & 0.006 & -0.017 & 0.002 & $-9 \cdot 394$ & 0.001 \\
\hline Emotional Maturity & -0.010 & 0.002 & -4.473 & 0.001 & -0.014 & 0.001 & -11.676 & 0.001 \\
\hline Emotional Competency & -0.015 & 0.002 & $-7 \cdot 398$ & 0.001 & -0.014 & 0.001 & -14.449 & 0.001 \\
\hline
\end{tabular}

The results presented in Table 8, indicated that the three predictor variables emotional sensitivity, emotional maturity, and emotional competency contributed $94 \%$ (doctors) and
$90 \%$ (nurses) of variance in aversive/noxious exposures. The contributions made by all the three dimensions of emotional intelligence on aversive/noxious exposures were significant.

Table 8: Relationship of Emotional Intelligence with Aversive/Noxious Exposures

\begin{tabular}{|c|c|c|c|c|c|c|}
\hline \multirow{3}{*}{ Model } & \multicolumn{4}{|c|}{ Model Summary } & \multirow{2}{*}{\multicolumn{2}{|c|}{ F- Statistics }} \\
\hline & $\mathbf{R}$ & R Square & Adjusted R & Std. Error of the Estimate & & \\
\hline & & & Square & & $\mathbf{F}$ & Sig \\
\hline Doctors & $0.972^{\mathrm{a}}$ & 0.945 & 0.943 & 0.27678 & 721.900 & 0.001 \\
\hline Nurses & $0.953^{\mathrm{a}}$ & 0.907 & 0.906 & 0.29014 & 828.497 & 0.001 \\
\hline
\end{tabular}




\section{Regression Coefficients}

Predictor Variables Doctors

\begin{tabular}{lcccccrrr} 
& $\boldsymbol{\beta}$ & $\begin{array}{c}\text { Std. Er- } \\
\text { ror }\end{array}$ & $\mathbf{t}$ & Sig. & $\boldsymbol{\beta}$ & Std. Error & t & \\
Emotional Sensitivity & -0.026 & 0.003 & -7.883 & 0.001 & -0.023 & 0.003 & -8.652 & 0.001 \\
Emotional Maturity & -0.024 & 0.002 & -10.574 & 0.001 & -0.021 & 0.002 & -12.153 & 0.001 \\
Emotional Compe- & -0.025 & 0.002 & -12.258 & 0.001 & -0.026 & 0.001 & -18.109 & 0.001 \\
tency & & & & & & & \\
\hline
\end{tabular}

The results presented in Table 9, indicated that the three predictor variables emotional sensitivity, emotional maturity, and emotional competency contributed 79\% (doctors) and $74 \%$ (nurses) of variance in threat-avoidant vigilance/ disaster potential. The contributions made by all the three dimensions of Emotional intelligence on Threat-avoidant vigilance/disaster potential were significant.

Table 9: Relationship of Emotional Intelligence with Threat-Avoidant Vigilance/Disaster Potential

\begin{tabular}{|c|c|c|c|c|c|c|c|c|}
\hline \multicolumn{9}{|l|}{ Model Summary } \\
\hline \multirow[t]{2}{*}{ Model } & \multirow[t]{2}{*}{$\mathbf{R}$} & \multirow[t]{2}{*}{ R Square } & \multirow{2}{*}{$\begin{array}{l}\text { Adjusted R } \\
\text { Square }\end{array}$} & \multirow{2}{*}{\multicolumn{3}{|c|}{ Std. Error of the Estimate }} & \multicolumn{2}{|c|}{ F- Statistics } \\
\hline & & & & & & & $\mathbf{F}$ & Sig \\
\hline Doctors & $0.883^{\mathrm{a}}$ & 0.779 & \multicolumn{2}{|l|}{0.774} & \multicolumn{2}{|c|}{1.04766} & 149.432 & 0.001 \\
\hline Nurses & $0.860^{\mathrm{a}}$ & 0.740 & \multicolumn{2}{|l|}{0.737} & \multicolumn{2}{|c|}{0.88755} & 240.794 & 0.001 \\
\hline \multicolumn{9}{|c|}{ Regression Coefficients } \\
\hline \multirow[t]{2}{*}{ Predictor Variables } & \multicolumn{4}{|c|}{ Doctors } & \multicolumn{4}{|c|}{ Nurses } \\
\hline & $\beta$ & Std. Error & $\mathbf{t}$ & Sig. & $\beta$ & Std. Error & $\mathbf{t}$ & Sig. \\
\hline Emotional Sensitivity & -0.010 & 0.012 & -0.836 & 0.405 & -0.038 & 0.008 & -4.639 & 0.001 \\
\hline Emotional Maturity & -0.061 & 0.008 & -7.230 & 0.000 & -0.041 & 0.005 & -7.755 & 0.001 \\
\hline Emotional Competency & -0.045 & 0.008 & -5.885 & 0.000 & -0.039 & 0.004 & -8.878 & 0.001 \\
\hline
\end{tabular}

The results presented in Table 10, indicated that the three predictor variables emotional sensitivity, emotional maturity, and emotional competency contributed 97\% (doctors) and
93\% (nurses) of variance in conflict/uncertainty. The contributions made by all the three dimensions of emotional intelligence on conflict/uncertainty were significant.

Table 10: Relationship of Emotional Intelligence with Conflict/Uncertainty

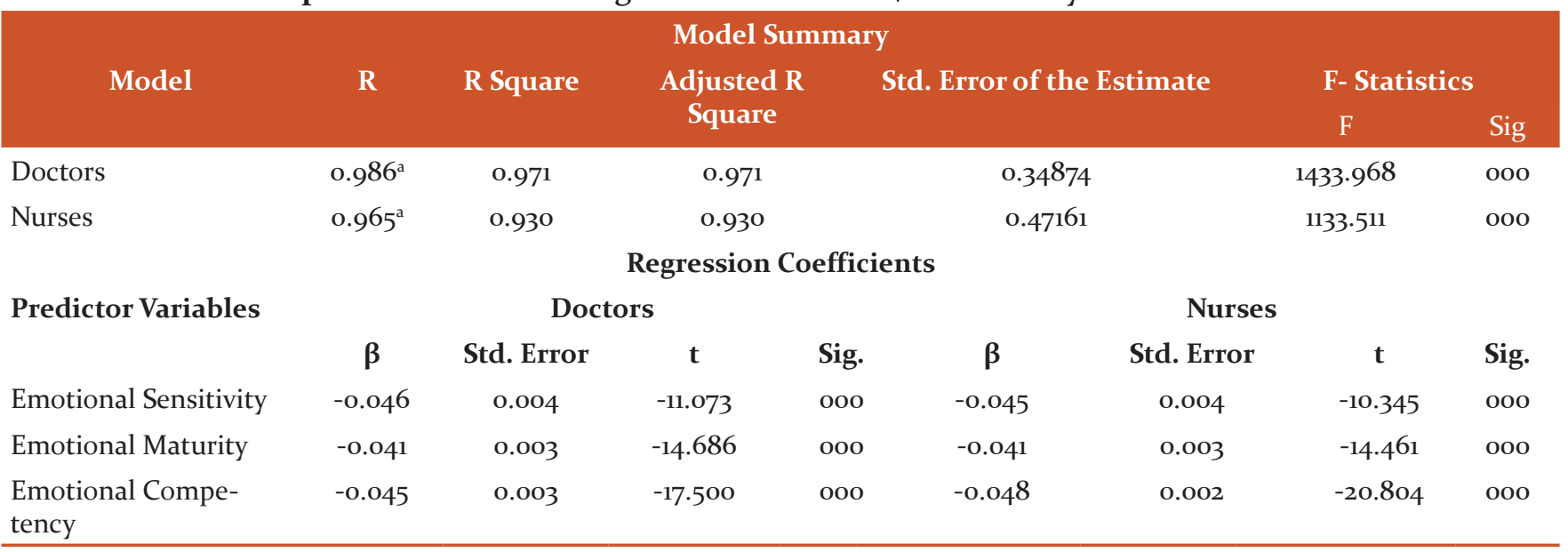


The results presented in Table 11, indicated that the three predictor variables emotional sensitivity, emotional maturity, and emotional competency contributed $70 \%$ (doctors) and
$86 \%$ (nurses) of variance in perceived stress. The contributions made by all three dimensions of emotional intelligence on perceived stress were significant.

Table 11: Relationship of Emotional Intelligence with Perceived Stress

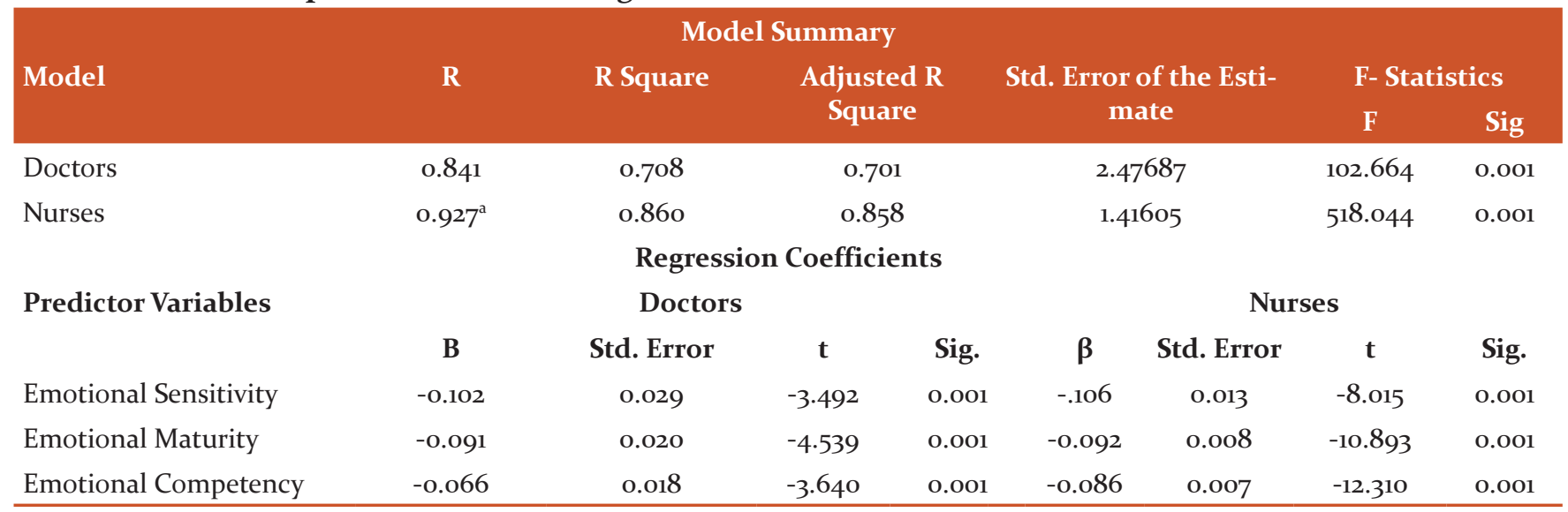

The results presented in Table 12, indicated that the three predictor variables Emotional Sensitivity, Emotional Maturity, and Emotional Competency contributed 74\% (doctors) and $89 \%$ (nurses) of variance in Emotional Exhaustion. The contributions made by all the three dimensions of Emotional intelligence on with Emotional Exhaustion were significant.

Table 12: Relationship of Emotional Intelligence with Emotional Exhaustion

\begin{tabular}{|c|c|c|c|c|c|c|c|c|}
\hline & & & el Sumı & & & & & \\
\hline Model & $\mathbf{R}$ & R Square & Adjus & $\mathbf{R}$ & Std. Erro & of the & $\mathbf{F}-\mathbf{S t}$ & \\
\hline & & & Squ & & Estin & ate & $\mathbf{F}$ & Sig \\
\hline Doctors & $0.891^{\mathrm{a}}$ & 0.794 & 0.7 & & 1.97 & & 162.690 & 0.001 \\
\hline Nurses & $0.947^{\mathrm{a}}$ & 0.896 & 0.8 & & 1.21 & & 731.660 & 0.001 \\
\hline Regression Coefficients & & & & & & & & \\
\hline Predictor Variables & & Doctor & & & & & rses & \\
\hline & B & Std. Error & $\mathbf{t}$ & Sig. & $\beta$ & $\begin{array}{l}\text { Std. Er- } \\
\quad \text { ror }\end{array}$ & $\mathbf{t}$ & Sig. \\
\hline Emotional Sensitivity & -0.063 & 0.023 & -2.698 & 0.008 & -0.066 & 0.011 & -5.820 & 0.001 \\
\hline Emotional Maturity & -0.101 & 0.016 & -6.286 & 0.001 & -0.090 & 0.007 & -12.444 & 0.001 \\
\hline Emotional Competency & -0.082 & 0.014 & -5.661 & 0.001 & -0.109 & 0.006 & -18.244 & 0.001 \\
\hline
\end{tabular}

The results presented in Table 13, indicated that the three predictor variables emotional sensitivity, emotional maturity, and emotional competency contributed $83 \%$ (doctors) and
$86 \%$ (nurses) of variance in depersonalization. The contributions made by all the three dimensions of emotional intelligence on with depersonalization were significant.

Table 13: Relationship of Emotional Intelligence with Depersonalization

\begin{tabular}{|c|c|c|c|c|c|c|}
\hline \multicolumn{7}{|c|}{ Model Summary } \\
\hline \multirow[t]{2}{*}{ Model } & \multirow[t]{2}{*}{$\mathbf{R}$} & \multirow[t]{2}{*}{ R Square } & \multirow{2}{*}{$\begin{array}{l}\text { Adjusted R } \\
\text { Square }\end{array}$} & \multirow{2}{*}{$\begin{array}{l}\text { Std. Error of the Esti- } \\
\text { mate }\end{array}$} & \multicolumn{2}{|c|}{ F- Statistics } \\
\hline & & & & & $\mathbf{F}$ & Sig \\
\hline Doctors & 0.911 & 0.831 & 0.827 & 1.82210 & 207.681 & 0.001 \\
\hline Nurses & 0.930 & 0.864 & 0.863 & 1.29115 & 538.869 & 0.001 \\
\hline
\end{tabular}

\section{Regression Coefficients}

Predictor Variables

Doctors

Nurses

$\begin{array}{llllllll}\text { B } & \text { Std. Error } & \mathrm{t} & \text { Sig. } & \boldsymbol{\beta} & \text { Std. Error } & \mathrm{t} & \text { Sig. }\end{array}$




\begin{tabular}{lllllllll} 
Emotional Sensitivity & -0.103 & 0.022 & -4.774 & 0.001 & -0.125 & 0.012 & -10.427 & 0.001 \\
Emotional Maturity & -0.100 & 0.015 & -6.792 & 0.001 & -0.081 & 0.008 & -10.498 & 0.001 \\
Emotional Competency & -0.067 & 0.013 & -5.056 & 0.001 & -0.070 & 0.006 & -10.937 & 0.001 \\
\hline
\end{tabular}

Winding up, the results of various regression analyses suggested that in general, the dimensions of emotional intelligence, emotional sensitivity, emotional maturity, and emotional competency have been reported to significantly predict the all the seven dimensions of occupational stress and the dimensions of burnout and the order and strength of the predictors differ across the two groups of healthcare professionals.

\section{CONCLUSIONS}

The study justifies the main assumption of the research that high emotional intelligence leads to lower occupational stress among healthcare professionals. This study also indicated that occupational stress among health care professionals can be reduced by not only by decreasing or controlling the stressors present in the workplace but also by increasing the potential of employees to effectively deal with those stressors. Increasing the emotional sensitivity, competency and maturity can help the healthcare professionals deal more effectively with the stress present in the workplace which indirectly leads to better work performance.

\section{IMPLICATIONS}

The findings of the study emphasize the use of emotional intelligence for assessments and academic results as a prerequisite to entering the profession. The incorporation of an emotional intelligence test in recruitment and selection procedures seems to improve the projecting validity of the selection method. The study also suggests emotional intelligence as a tool for reducing the stress related to health care professionals. Apart from all these the study also highlights the need to develop intervention programs specifically aimed at increasing the EI level and reducing occupational stress.

\section{FUTURE RESEARCH}

The study can be considered as a basis for research focusing on cognitive ergonomics dimensions of occupational stress rather than sociological theory which was ignored by earlier studies in the field of emotional intelligence. A similar study can be undertaken with a larger sample comparing different types of healthcare setting like CHC's, PHC's and district hospitals separately as different types of healthcare setting has different work environment and constrains and stressors which result in different stress levels among healthcare professionals employed in the different healthcare setting.

\section{ACKNOWLEDGEMENT}

Authors acknowledge the immense help received from the scholars whose articles are cited and included in references to this manuscript. The authors are also grateful to authors/editors/publishers of all those articles, journals and books from where the literature for this article has been reviewed and discussed.

\section{Conflict of Interest: Nil}

\section{Source of Funding: Nil}

\section{REFERENCES}

1. Williams SJ, Gabe J, \& Calnan M. (Eds.). Health, medicine, and society: Key theories, future agendas. Psychology Press; 2000.

2. Brand T. An exploration of the relationship between burnout, occupational stress and emotional intelligence in the nursing industry (Doctoral dissertation, 2007. Stellenbosch: University of Stellenbosch).

3. Montgomery A, Panagopoulou E, Kehoe I, Valkanos E. Connecting organisational culture and quality of care in the hospital: Is job burnout the missing link? J Heal Organ Manag 2011; 25(1):108-23.

4. Freudenberger HJ, Richelson G. Burn-out : the high cost of high achievement. 1st ed. Norwenn, MA: Anchor Press; 1980.

5. Kristensen TS, Borritz M, Villadsen E, Christensen KB. The Copenhagen Burnout Inventory: A new tool for the assessment of burnout. Work Stress 2005; 19(3):192-207.

6. Shirom A, Melamed S. Does burnout affect physical health? A review of the evidence. In: Antoniou AS., Cooper CL, editors. A research companion to organizational health psychology. Northampton, MA, US: Edward Elgar Publishing. 2005.

7. Maslach C, Leiter MP. The Truth About Burnout : How Organizations Cause Personal Stress and What to Do About It. San Francisco, CA, US: Jossey-Bass; 2008.

8. Maslach C, Schaufeli WB, Leiter MP. Job Burnout. Annu Rev Psychol 2001;52(1):397-422.

9. Kheirmand M, Kheirmand F, Pazhouhan A. The relationship between emotional intelligence and occupational stress among nurses of Alzahra Hospital in Isfahan. Q Hosp 2016; 15(1):5968.

10. Cherniss, C. Emotional Intelligence: Towards a clarification of a concept. Indus Organiz Psychol 2010; 3:110-126.

11. Freudenberger HJ, Richelson G. Burn-out : the high cost of high achievement. 1st ed. Anchor Press; 1980.

12. Kristensen TS, Borritz M, Villadsen E, Christensen KB. The Copenhagen Burnout Inventory: A new tool for the assessment of burnout. Work Stress 2005; 19(3):192-207. 
13. Shirom A, Melamed S. Does burnout affect physical health? A review of the evidence. In: Antoniou AS., Cooper CL, editors. Research companion to organizational health psychology. Northampton, MA, US: Edward Elgar Publishing; 2005.

14. Collings JA, Murray PJ. Predictors of stress amongst social workers: An empirical study. Br J Soc Work 1996; 26(3):375-87.

15. Singh D, Chadha NK. The emotional quotient test. 1st ed. New Delhi: SAGE Publications Inc; 2001.

16. Belkic K, Savic C. Job stressors and mental health: a proactive clinical perspective. World Scientific; 2013.

17. Cohen S, Kamarck T, Mermelstein R. A global measure of perceived stress. J Health Soc Behav 1983; 24(4):385-96.

18. Demerouti E, Nachreiner F, Bakker AB, Schaufeli WB. The job demands-resources model of burnout. J Appl Psychol 2001; 86(3):499-512.
19. Punia BK. Impact of Demographic Variables on Emotional Intelligence and Leadership Behaviour of Corporate Executives. IUP J Organis Behav 2005; 4(2), 7-22.

20. Rajkhowa R. Emotional Intelligence of IAS officers. University of Delhi, India; 2002

21. Singh, D. EQ and managerial effectiveness: An international study. Bundelkhand University, Jhansi, India; 2005.

22. Birks Y, McKendree J, Watt I. Emotional intelligence and perceived stress in healthcare students: a multi-institutional, multiprofessional survey. BMC Med Edu 2009;9(1):61.

23. Khanam N, Sahu T, Rao E V, Gaidhane AM. A study on various dimensions of emotional intelligence among doctors. Int J Community Med Public Health 2017; 5(1):390. 